\title{
O DISCURSO DO ESPAÇO E A REPRESENTAÇ̃̃O DO TRIBUNAL: AS RELAÇÕES ENTRE THE CHILDREN ACT E BLEAK HOUSE
}

http://dx.doi.org/10.11606/issn.2237-1184.v0i24p27-43

Cássia Escoza

Universidade de São Paulo (USP)

RESUMO

Este artigo propõe uma análise comparativa entre as obras Bleak House (1853), de Charles Dickens e The Children Act (2014), de Ian McEwan, com base nos estudos semióticos da figuratividade. A observação das semelhanças e diferenças do discurso do espaço nos dois romances viabiliza a compreensão dos aspectos estilísticos e formais utilizados pelos autores, bem como do contexto histórico-cultural em que as obras surgiram. Mais especificamente, esta análise revela a estreita conexão das narrativas sobre a relação entre a literatura e os processos jurídicos na sociedade inglesa, em meados do século XIX e início do século XXI.

\section{ABSTRACT}

This article proposes a comparative analysis between the works Bleak House (1853) by Charles Dickens and The Children Act (2014) by Ian McEwan, using figurative semiotic studies. Observing the similarities and differences of the narrative space contained within the two novels, enables the understanding of the stylistic and formal aspects used by these authors as well as the historical and cultural context in which they arose. The analysis reveals the close connection between the two narratives, more specifically, the relationship between literature and legal processes of English society in the mid-nineteenth century and early twenty-first century.
PALAVRAS-CHAVE:

Charles Dickens.

Ian McEwan.

Semiótica figurativa.

Literatura e Direito.

KEYWORDS:

Charles Dickens.

Ian McEwan.

Figurative semiotics.

Law and Literature.

${ }^{1}$ Doutora em Letras pela Universidade Estadual Paulista (UNESP). Pós - doutoranda em Letras na Universidade de São Paulo (USP). Email: caescoza@hotmail.com 


\section{ntrodução: A realidade verificável}

Este artigo apoia-se nos recursos da Literatura Comparada para investigar os aspectos estilísticos e formais que estruturam as obras Bleak House $(1852)^{2}$ e The Children Act $(2014)^{3}$, no intuito de compreender os elementos literários e o contexto social em que esses romances surgiram.

O estudo também se fundamenta na definição semiótica de Denis Bertrand $(2003)^{4}$, sobre o estatuto da figuratividade, compreendida por ele dessa forma:

todo conteúdo de um sistema de representação (visual, verbal ou outro) tem um correspondente no plano da expressão do mundo natural, isto é, da percepção. As formas de adequação, configuradas pelo uso, entre a semiótica do mundo natural e a das manifestações discursivas, formam o objeto da semiótica figurativa. Esta se interessa, pois, pela representação, (a mimeses), pelas relações entre figuratividade e abstração, pelos vínculos entre a atividade sensorial da percepção e as formas de discursivização. (BERTRAND, 2003, p. 420).

Assim, o trabalho examina o discurso concreto de representação nas narrativas, tanto do mundo exterior quanto dos acontecimentos, e o discurso abstrato que diz respeito à eficácia simbólica das representações nos dois romances da literatura inglesa, no intuito de refletir sobre como o texto literário estrutura uma significação do universo descritível e visível.

A análise privilegia a abordagem do discurso espacial pela relevância de como ele se estrutura nas obras, e mais especificamente, porque esse viés pode conduzir ao entendimento dos procedimentos jurídicos em relação ao contexto e às circunstâncias em que eles se circunscrevem nesses livros dos dois autores.

Bleak House é o nono romance de Charles Dickens e foi publicado em vinte fascículos entre março de 1852 e setembro de 1853, e em um único volume ainda no ano de 1853. A principal temática da obra é o sistema legal da era vitoriana. Nessa época, havia na Inglaterra duas cortes, a de Common Law, que tratava de casos como assassinatos e roubos e a de Chancery, criada no período medieval para resolver casos de propriedades,

2 DICKENS, Charles. Bleak House. [ebook\#1023] www.gutenberg.org .1853.

${ }^{3}$ MCEWAN, Ian. The Children Act. London: Jonathan Cape, 2014b.

${ }^{4}$ BERTRAND, Denis. Caminhos da semiótica literária. Bauru/SP: Edusc, 2003. 
heranças, dívidas, problemas de família, entre outros. É sobre a corte de Chancery que a narrativa de Dickens dispara as suas críticas, apontando as falhas desse tribunal e o efeito delas na vida das personagens. São várias as causas julgadas nesse extenso livro de 67 capítulos, sendo a mais relevante delas a questão testamentária Jarndyce and Jarndyce.

Trata-se de uma ação judicial estabelecida na corte de Chancery, que se arrasta por gerações e só alcança um desfecho no último capítulo da obra, quando à custa do processo já consumiram toda a herança. As personagens que se envolvem diretamente com a causa têm destinos trágicos: Miss Flite enlouqueceu, Richard Carstone definhou até a morte tentando receber sua parte, Mr. Jarndyce suicidou-se por não suportar a morosidade do julgamento. A única personagem a se manter livre dos malefícios provenientes do trâmite jurídico é John Jarndyce, o qual procura se manter o mais distante possível da causa.

Já The Children Act, publicado em 2014, trata do sistema jurídico atual da Inglaterra, sobretudo, da Corte da Vara de Família. Os casos recriados por McEwan referem-se a divórcios, divisão de propriedades, direitos das crianças e demandas sobre a guarda dos filhos. A maioria dos processos reflete um conflito proveniente de divergências religiosas. $\mathrm{O}$ mais detalhado deles é o caso de Adam Henry, um rapaz de 17 anos, testemunha de Jeová que, hospitalizado para se tratar de leucemia, recusase a aceitar uma transfusão de sangue por causa de sua crença.

A leitura das duas obras revela, constantemente, a predileção desses autores pela recriação do real com alto índice de fidelidade dentro da moldura literária. Ian McEwan é conhecido por se aprofundar em pesquisas para compor suas narrativas. Antes de escrever Saturday (2005) ele passou dois anos assistindo a várias cirurgias neurológicas, fazendo entrevistas com médicos e consultando livros sobre o assunto; em Atonement (2002) há muitas referências colhidas nos documentos do Museu Imperial da Guerra; para compor The Children Act, o autor afirmou ter lido cadernos de sentenças de amigos juízes e discutido o tema com eles.

A crítica de Charles Dickens dá sempre importância ao modo de o escritor de observar a realidade e recriá-la com minúcias em suas narrativas. Em Literary Studies, Berghot $(1911)^{5}$ afirma sobre o autor: "Ele pode descer uma rua movimentada, e contar tudo que há nela, o que cada loja era, qual o nome da mercearia, quantos pedaços de casca de laranja havia no chão. Suas obras dão a você a mesma ideia" (BERGHOT, p. 173, tradução nossa). ${ }^{6}$

\footnotetext{
${ }^{5}$ BERGHOT, Walter. Literary Sudies. Vol.2. Dent.: London, 1911.

${ }^{6} \mathrm{He}$ can go down a crowded street, and tell you all that is in it, what each shop was, what the grocer's name was, how many scraps of orange-peel there were on the pavement. His works give you the same idea (BERGHOT, 1911, p. 173).
} 
Dickens conhecia bem os meandros das instituições jurídicas inglesas. Segundo seu biógrafo e amigo John Foster ${ }^{7}$, ainda na infância, o escritor conviveu com a dura realidade de ter seu pai preso por dívidas. Aos quinze anos, trabalhou como clerck (escriturário de advogados) e aos dezoito, ocupou-se como repórter na Corte. Em 1844, entrou com uma petição judicial contra publicações pirateadas de sua obra Christmas Carol. Mesmo tendo vencido a causa, precisou arcar com as altas despesas do processo.

A informação bem detalhada é um preceito básico para gerar o efeito de uma realidade verificável, entretanto, a excelência dos autores estudados está justamente em extrapolar o empirismo e recriá-lo pela atividade ficcional. Esse novo mundo, autônomo, preserva sempre um vínculo com o real, mas é narrado pela linguagem literária, portanto, carrega em si uma concentração de dimensões significativas, capazes de ampliar o entendimento dos fatos, da alma humana, dos sentimentos, da possibilidade de uma compreensão estética que aponte para uma circunstância moral e traga à luz problemas sociais para despertar no leitor a necessidade de refletir sobre os costumes e mudanças.

\section{A intertextualidade}

Nos romances de Ian McEwan, é frequente o uso do diálogo com a tradição literária. Esse artifício de conexão, que permite ao autor resgatar elementos do passado e até renová-los, constitui-se como um dos elementos caros à literatura comparada, o da intertextualidade, proposta por Júlia Kristeva $(1974)^{8}$ como a interação entre textos. Para ela, "todo texto se constrói como mosaico de citações, todo texto é absorção e transformação de um outro texto" (p. 64).

The Children Act apresenta algumas vezes implícitas, outras ostensivas, o uso da intertextualidade com o romance de Charles Dickens. A frase inicial da obra de McEwan: "London. Trinity term one week old. Implacable June weather. Fiona May, a High Court judge, at home on Sunday evening, supine on a chaise longue" (MCEWAN, 2004b, p. 1) , é $^{9}$ uma clara referência à abertura de Bleak House: "London. Michaelmas term lately over, and the Lord Chancellor sitting in Lincoln's Inn Hall. Implacable November weather" (DICKENS, 1853, p. 18). ${ }^{10}$

\footnotetext{
${ }^{7}$ FOSTER, John. The Life of Charles Dickens. Disponível em: https://www.lang.nagoya-u.ac.jp/ matsuoka/CDForster-1.html. Acesso em 22/07/2016, às 9h20.

${ }^{8}$ KRISTEVA, Julia. Introdução à semanálise. São Paulo: Perspectiva, 1974.

${ }^{9}$ As traduções da obra The Children Act são de Jorio Dauster, responsável pela versão em português: A balada de Adam Henry, publicada pela Companhia das Letras, em 2014. "Londres. Sessões do tribunal encerradas havia uma semana. O tempo implacável de junho. Fiona May, juíza do Tribunal Superior, em casa na noite de domingo e deitada numa chaise longue"(MCEWAN, 2014a, p. 09). MCEWAN, Ian. A balada de Adam Henry. Trad. Jorio Dauster. São Paulo: Companhia das Letras, 2014a.

${ }^{10}$ Todas as traduções de Bleak House são de Oscar Mendes, tradutor da obra para o português sob o título A casa soturna, pela Editora Nova Fronteira, publicada em 1986. "Londres. As férias forenses da festa de São Miguel acabaram e o Lorde Chanceler está dando audiência no Lincoln's Inn Hall. Temperatura aspérrima de novembro"
} 
No fragmento de Bleak House, observa-se a referência ao Lincoln's Inn Hall na cidade de Londres. "Inns" eram edifícios onde ficavam as sociedades dos advogados na época de Dickens, como: Inner Temple, Middle Temple, Gray's Inn e Lincoln's Inn. Todos eles ainda fazem parte da arquitetura londrina atual. Esse último é o maior deles, situado no Bairro de Holborn, entre a parte central da cidade e Westminster. Constituía-se, no século XIX, de dois quadrângulos, nos quais ficavam as salas dos advogados e procuradores, um salão, onde se davam alguns julgamentos e uma livraria.

A Corte de Chancery se estabelecia em alguns "termos" no Lincoln's Inn. Termos são as denominações dadas aos períodos do ano nos quais ocorrem as atividades das cortes inglesas: Hilary (de janeiro a abril), Easter (de abril a maio), Trinity (de junho a julho) e Michaelmas (de outubro a dezembro). Esse calendário também é adotado por algumas universidades como Cambridge e Oxford para a divisão dos períodos de aulas.

A época do ano informada na abertura do romance de Dickens, "Michaelmas term", em novembro, corresponde ao inverno inglês, que o adjetivo "implacable" (implacável) determina como rigoroso, difícil. O sujeito que aparece nesse tempo-espaço é o Lord Chancellor, autoridade máxima da corte de Chancery, que resolvia os casos do tribunal sem a ajuda de juízes, baseando-se apenas nas evidências trazidas pelos advogados.

Do texto de origem, na abertura de seu romance, McEwan retoma o bairro de Holborn na cidade de Londres como espaço da narrativa e modifica o período de tempo, de "Michaelmas term", para "Trinity term", ligando o adjetivo "implacável" ao verão, considerando, portanto, as difíceis condições climáticas do país também em uma estação que deveria ser de clima ameno. O sujeito que aparece em The Children Act é Fiona May, uma juíza da alta corte, correspondendo à figura do Chanceler.

A escolha de McEwan pela personagem do sexo feminino e como juíza revela a distância temporal entre as narrativas e as diferenças que se operaram nas instituições jurídicas da Inglaterra desde a época vitoriana até a atualidade, visto que no período recriado por Dickens as mulheres não ocupavam posições como a de Chanceler e que esse cargo foi alterado para o de juiz. Enquanto a personagem de Bleak House aparece na corte "sitting in" ao invés de "in sitting", ou seja, sentado e não declarando aberta ou estabelecendo a corte, Fiona May é apresentada em sua casa, em um final de tarde de domingo e reclinada em sua chaise longue.

No desenvolvimento deste início de narrativa, a postura do Chanceler, sentado e com o olhar fixo no lustre da sala, sugere a sua falta de atenção com as demandas da corte, e, se em um primeiro momento, a juíza, também foi descrita em atitude inerte, logo o narrador revela que,

(DICKENS, 1986, p. 09). DICKENS, Charles. A casa soturna. Trad. Oscar Mendes. Rio de Janeiro: Nova Fronteira, 1986. 
embora seja uma tarde de domingo, ela tem perto de si laudas de uma causa judicial na qual está trabalhando. Assim, desde o início, essas personagens distinguem-se quanto à eficiência. O Chanceler é sempre retratado como improdutivo e a juíza, produzindo demais. O fato de trabalhar em casa aponta tanto para o excesso de atividade quanto para uma realidade contemporânea, que é diluição das fronteiras entre o ambiente de trabalho e o doméstico.

O início dos dois romances oferece indícios de um discurso próprio do Direito, revelando a temática jurídica a ser abordada pelos autores. É evidente que a referência ostensiva de McEwan ao romance de Dickens prenuncia um diálogo com a obra de origem.

Embora o romance de McEwan seja muito mais conciso do que o de Dickens, há uma similaridade quanto à arquitetura da narrativa, de modo que os capítulos não se entrelaçam em uma linearidade rigorosa, pois cada um deles trata de um tópico e termina com um clímax que não se desenvolve no seguinte, mas será conectado em outro capítulo posicionado mais adiante na narrativa. Esse recurso, que certamente assegura o interesse do leitor, confere um aspecto intrincado à história, alinhando-se ao andamento dos procedimentos legais recriados nas narrativas.

\section{A estruturação do espaço}

Uma das conexões bem relevante nos dois romances é a estruturação do espaço. Ambos demonstram a preocupação dos autores em estabelecer uma relação entre o real e o sensível, entre o aspecto visível e o inteligível daquilo que é retratado, de modo a gerar uma espécie de "convicção" para o leitor, uma compreensão não apenas objetiva, mas subjetiva e intelectiva do ambiente.

Denis Bertrand, em seu estudo contrastivo entre La Bête Humaine $(1890)^{11}$ de Zola e L'Acacia (1989) de Claude Simon, prioriza a análise do discurso espacial, pois para ele, nessas obras, as figuras do espaço extrapolam sua atribuição referencial, regulando os níveis figurativos e abstratos de leitura para assegurar a eficácia da recepção:

O sistema espacial assegura a coesão recíproca de um discurso dos acontecimentos e de um discurso "hermenêutico" que dizem respeito ao progresso social e político da humanidade (BERTRAND, 2008, p. 152).

Com base nessa reflexão de Bertrand, nota-se que as obras estudadas neste artigo se utilizam de uma construção do discurso do espaço de

\footnotetext{
${ }^{11}$ BERTRAND, Denis. "A linguagem espacial em La Bête Humaine". Trad. Geraldo Majela de Morais Santos. Revista InterteXto. V.1, n. 2. Uberaba: UFTM, 2008, pp. 147-166.
} 
maneira a estabelecer um vínculo interpretativo entre o sensível e o inteligível e a revelar o contexto histórico-social retratado nas narrativas.

Em The Children Act, os casos são julgados na Royal Courts of Justice, onde funciona a Court of Appeal, que inclui a divisão de família. Esta se localiza no bairro de Holborn, nas proximidades do Lincoln's Inn, portanto, praticamente no mesmo local de Londres retratado em Bleak House. Evidentemente, esse espaço sofreu algumas modificações nos séculos que separam as obras; ainda assim, parte do Lincoln's Inn restaurada mantém a mesma estrutura da época vitoriana.

No romance de Dickens, o recurso de estruturação espacial conta principalmente com dois elementos que se repetem à exaustão na narrativa: a lama (mud) e a névoa (fog). Já no primeiro capítulo, no qual a Corte de Chancery é apresentada, a palavra "fog" aparece 21 vezes, além de outros termos e expressões que reforçam a atmosfera carregada, como "smoke" (fumaça); "soft black drizzle" (garoa leve e escura); "flakes of soot" (flocos de fuligem); "misty clouds" (nuvens de névoa); "raw" (nevoenta); "rawest" (mais nevoenta); "foggy" (nebuloso); "mistily" (nevoentamente); "dim" (sombrio) e "murky" (fosca).

A palavra "mud" (lama) também se repete continuamente e é realçada pelos sinônimos: "mire" (lodaçal); "splashed" (enlameados); "losing their foot-hold" (para designar que as pessoas escorregavam na lama); "sliding" (escorregando); "crust of mud" (crostas de lama); "muddy streets are muddiest" (ruas enlameadas e mais lamacentas ainda).

O fragmento seguinte ilustra a utilização desses elementos:

Nevoeiro por toda a parte. Nevoeiro rio acima, onde este corre entre verdes ilhotas e campinas; nevoeiro rio abaixo, onde ele rola, sujo, entre os renques das embarcações e a sujeira das praias duma grande cidade (grande e imunda).

(...). Acenderam-se as luzes na maior parte das lojas duas horas antes do costume, o que parece não ter agradado ao gás, pois se mostrava macilento e maldisposto.

A tarde nevoenta é mais nevoenta, mais denso o denso nevoeiro e as ruas enlameadas mais lamacentas ainda, perto daquela velha barreira, encimada de chumbo, apropriado elemento para o limiar duma velha corporação de cabeças de chumbo - Templo Bar. E perto de Templo Bar, no Lincoln's Inn Hall, mesmo no coração do nevoeiro, exerce suas funções S. Exa. o Lorde Chanceler, na sua Alta Corte de Justiça (DICKENS, 1986, p. 9-10). ${ }^{12}$

Considerando, em um primeiro momento, apenas os aspectos visíveis da descrição do espaço, observa-se uma correspondência com a

\footnotetext{
12 Fog everywhere. Fog up the river, where it flows among green aits and meadows; fog down the river, where it rolls defiled among the tiers of shipping and the waterside pollutions of a great (and dirty) city.

(...) Most of the shops lighted two hours before their time - as the gas seems to know, for it has a haggard and unwilling look.

The raw afternoon is rawest, and the dense fog is densest, and the muddy streets are muddiest near that leadenheaded old obstruction, appropriate ornament for the threshold of a leaden-headed old corporation, Temple Bar. And hard by Temple Bar, in Lincoln's Inn Hall, at the very heart of the fog, sits the Lord High Chancellor in his High Court of Chancery (DICKENS, 1853, p. 19-21).
} 
realidade de Londres no período retratado na obra, entre 1830 e 1850. Nessa época, embora a cidade fosse a capital cultural da Europa, estivesse em pleno sucesso na expansão marítima e em desenvolvimento da revolução industrial, o rápido crescimento da população, o desnível social gritante, a falta de estruturas básicas de saneamento e outras falhas de infraestrutura, formavam um ambiente sujo nas ruas não pavimentadas, cheias de poeira e lama, estrume de cavalos, dejetos das fábricas, esgoto a céu aberto, muita fumaça escura - tanto pela poluição das fábricas quanto pela iluminação a gás.

Observa-se no fragmento anterior um recurso quase cinematográfico de representação, como se o ângulo de visão do narrador correspondesse a uma câmera e partisse das margens do rio Tâmisa, atravessasse o bairro de Holborn, aproximando-se das construções onde se situavam os tribunais, invadisse o salão de Lincoln's Inn, no qual se estabelecia a Corte de Chancery, concentrando um close na figura do Chanceler.

Durante todo esse percurso de focalização, a atmosfera carregada de sujeira e névoa vai se intensificando até atingir o auge de concentração dentro da Corte, em torno da autoridade máxima da casa. Essa reconfiguração mimética exprime um sentido abstrato ao espaço, que é exatamente o da falta de transparência, o da corruptibilidade desse tribunal e de seus membros.

De acordo com Sir William Holdsworth $(1929)^{13}$, professor de Direito na Universidade de Oxford e historiador das leis inglesas, a ineficiência da Corte de Chancery era bem conhecida pela população do país na época retratada em Bleak House. O sistema era abusivo, com oficiais despreparados para o trabalho, práticas burocráticas demais e muito lentas, manutenção de regras antigas para os procedimentos que aumentavam os atrasos e as despesas, como as cópias de documentos muitas vezes desnecessárias. Ele relata casos em que ações dessa corte estendiam-se por mais de cinquenta anos e consumiam fortunas dos envolvidos nos processos.

Em contrapartida à lama e à névoa do espaço reconfigurado em Bleak House, o romance de McEwan toma como elementos de repetição a chuva e o frio da área retratada:

Tinha chovido quase todos os dias desde o começo do verão, as árvores davam a impressão de ter inchado, suas copas alargadas, enquanto as calçadas estavam limpas e lisas, os carros reluzentes na revendedora da High Holborn. (...) Mas todos seguiam em frente, reclamando, resolutos, encharcados. As correntes atmosféricas tinham entrado em pane, curvadas em direção ao sul devido a fatores impossíveis de controlar, bloqueando o refrigério que vinha dos Açores no verão e sugando o ar gélido do Norte. Consequência das mudanças climáticas provocadas pelo homem que

${ }^{13}$ HOLDSWORTH, William S. Charles Dickens as a Legal Historian. New Haven/ Yale University Press. 1929. 
levavam ao derretimento das calotas polares e perturbavam as camadas superiores da atmosfera, ou de manchas solares irregulares que não eram culpa de ninguém ou fruto da variabilidade natural, ritmos antigos, o destino do planeta. (...)

Ao cruzar para a Chancery Lane, a chuva apertou, caindo na diagonal por conta de um vento frio e repentino. O dia escureceu, as gotas de chuva ricocheteavam em suas pernas como agulhas de gelo, as pessoas aceleravam o passo, silenciosas, absortas em seus pensamentos. O tráfego na High Holborn corria barulhento e vigorosamente destemido, os faróis brilhavam no asfalto (MCEWAN, 2004a, p. $44-45)^{14}$

O espaço que vai se delineando em The Children Act remete à cidade atual, e neste período, Londres não está mais tomada pela sujeira e névoa escura como no romance de Dickens, mas pela chuva e vento frio no verão, que o narrador procura explicar com os efeitos da mudança climática e de suas causas, um problema contemporâneo.

O percurso do ângulo de visão do narrador acompanha o trajeto da juíza de seu apartamento em Gray's Inn, passando pelo Gray's Inn Square, até a Chancery Lane, pela qual entra e atravessa o Lincoln's Inn, tomando em seguida uma passagem estreita que termina na livraria Wildy, a qual funciona ainda no mesmo lugar desde a época de Dickens, cruza, então, a Carey Street e chega atrás da Royal Court.

Atualmente, em Londres, esse espaço constitui um bairro nobre, todo pavimentado, no qual a maior parte das construções estão ocupadas com salas e residências de advogados e juízes, livrarias e lojas relacionadas ao funcionamento das cortes britânicas. A atmosfera desse ambiente está em clara oposição àquela retratada em Bleak House, embora ainda mantenha uma aura de obscuridade, captada no texto de McEwan pela chuva constante e pelo frio das ruas, como atesta o fragmento anterior, e pelo caráter labiríntico do trajeto da personagem nos corredores internos da instituição, como mostra o próximo excerto:

Subiu a escada em vez de pegar o elevador, pisando firme no carpete vermelho ao dobrar à direita em direção ao largo átrio repleto de portas dando acesso aos gabinetes de trabalho de vários magistrados do Tribunal Superior (...). Em cada recinto grande e coalhado de livros, seus colegas mergulhavam diariamente em seus casos e julgamentos, um labirinto de

\footnotetext{
${ }^{14}$ Rain had fallen most days of the summer, the city trees appeared swollen, their crests enlarged, the pavements were cleansed and smooth, the cars on High Holborn showroom clean. (...) But everyone pushed on, complaining, resolute, drenched. The jet stream was broken, bent southwards by factors beyond control, blocking the summer balm from the Azores, sucking in freezing air from the north. The consequence of man-made climate change, of melting sea ice disturbing the upper air, or irregular sunspot activity that was no one's fault, or natural variability, ancient rhythms, the planet's lot. (...)

By the time she was crossing the street to go down Chancery Lane, the rain was coming down harder, at a fair slant, driven by a sudden cold wind. Now it was darker, droplets bounced icily against her legs, crowds hurried by, silent, self-absorbed. Traffic along High Holborn poured past her, loud and vigorously undeterred, headlights gleaming on the asphalt (...) (MCEWAN, 2004b, p. 41 - 42).
} 
detalhes e controvérsias do qual somente certo estilo de gracejo e ironia oferecia alguma proteção (MCEWAN, 2014a, p. 49). ${ }^{15}$

Assim é que, ao estruturar o espaço em sua narrativa, McEwan atualiza um problema da justiça inglesa retratado na época de Dickens. Embora mudanças significativas tenham se operado nos séculos que separam os autores, como o fato do julgamento dos casos passar a ser feito por juízes, as cópias manuais terem dado espaço à digitalização nos computadores, garantindo mais rapidez e eficiência no processo, um dos aspectos que parece ter se mantido imutável é o acesso intrincado e difícil às leis. Na atualidade há muito mais transparência e rapidez nos trabalhos da corte, mas a frieza com que a lei ainda é aplicada em certos casos parece perdurar.

Outro ponto de encontro entre as duas obras está na utilização da alegoria para a estruturação do espaço. Em seu texto, Interpretation in Bleak House, J. Hills Miller (1971) aponta esse procedimento no romance de Dickens. Para o crítico, os espaços são apresentados pelos capítulos de maneira desconexa, mas na verdade, existe um entrecruzamento ligandoos, que precisa ser considerado pelo leitor: "Esse procedimento é alegórico no sentido estrito. Fala de uma coisa, falando de outra, como Dickens define o tribunal da chancelaria falando sobre uma loja de trapo e garrafa." (MILLER, 1971, p. 63, tradução nossa). ${ }^{16}$

Miller refere-se, no exemplo dado, ao alinhamento sugerido pela narrativa entre a corte e o armazém do Sr. Krook, abarrotado de garrafas sujas, livros estragados, velhos rolos de pergaminho, trapos de roupas de advogados, chaves enferrujadas, cabelos de mulheres, ossos de clientes e todo tipo de entulhos. Esses elementos associam-se à Chancery, principalmente quanto ao excesso de documentos, os quais levam os processos a uma contínua postergação e à permanência dos conflitos que parecem nunca ter solução, ao sofrimento dos litigantes, os quais muitas vezes morrem sem ter suas apelações atendidas, e, também, ao aspecto de sujeira e corrupção. Segundo o dono da loja, exatamente por não limpar nada, não consertar nada, e manter o ambiente superlotado é que seu armazém recebeu o nome de Tribunal.

Partindo da observação de Miller e do verbete no Dicionário de Termos Literários que define a alegoria como: "Uma linguagem que oculta outra, uma história que sugere outra. Empregando imagens, figuras, pessoas, animais, o primeiro discurso concretiza as ideias, qualidades ou entidades abstratas que compõem o outro". (LAUSBERG apud MOISÉS,

\footnotetext{
${ }^{15}$ She took the stairs rather than the lift, heavy footed on red carpet as she turned right towards her broad landing onto which the doors of many High Court Judges faced (...). In each broad and bookish room, her colleagues would lose themselves daily in their cases, their trials, in a labyrinth of detail and dissent against which only a certain style of banter and irony offered some protection (MCEWAN, 2004b, p. 46-47).

${ }^{16}$ This procedure is "allegorical" in the strict sense. It speaks of one thing by speaking of another, as Dickens defines the Court of Chancery by talking about a rag and bottle shop" (MILLER, 1971, p. 67).
} 
2004 , p. 14 ${ }^{17}$; observa-se o modo pelo qual os ambientes reconfigurados por Dickens mantêm uma relação alegórica entre si.

A descrição do bairro arruinado de Tom-All-Alone's: "essas habitações quase a cair abrigam de noite um enxame de miseráveis. Assim como num pobre diabo decadente aparece a bicharia parasitária (...) como vermes ali onde a chuva goteja" (DICKENS, 1986, p. 205), ${ }^{18}$ aponta para o aspecto de corrupção que emana da corte de Chancery, com seus advogados e funcionários do tribunal, retratados pelo autor, na maioria das vezes, como parasitas invadindo as salas de audiência.

Logo após descrever os navios ancorados e a zona portuária ao redor do Tâmisa, o próprio narrador estabelece uma correspondência alegórica entre esse espaço e os tribunais: "O Templo, o Beco do Tribunal, Sarjeant's Inn e Lincoln's Inn, até os Campos, são como portos de grandes marés na baixa-mar, onde processos encalhados, repartições ancoradas, escreventes ociosos (...) jazem altos e secos sobre a vaza das longas férias" (DICKENS, 1986, p. 240). ${ }^{19}$

Quando retrata as propriedades dos aristocratas, como a fazenda Chesney Wold, ou a casa em Lincolnshire, o narrador aponta para a dificuldade de manter os usos e costumes dessa classe nos tempos da revolução industrial e declara que tanto os nobres quanto o Tribunal fazem parte de um mundo amortecido, repleto de regras opostas à realidade vitoriana: "Tanto o mundo da alta roda como o Tribunal de Justiça são coisas de protocolo e de praxe" (DICKENS,1986, p. 15) ${ }^{20}$. Ele os compara a belas adormecidas que serão despertadas um dia "quando todos os espetos parados na cozinha começarem a girar prodigiosamente!" (DICKENS, 1986, p. 15) ${ }^{21}$. Assim, as imagens relacionadas a essas propriedades são construídas por um discurso que privilegia a lentidão e a morosidade, como "rio estagnado", "árvores melancólicas", "capelinha do parque cheia de bolor", "passeio do fantasma", "estéril pátio de tijolos". Os próprios donos dessas mansões, os Dedlocks, aparecem sempre entediados e desocupados.

Os escritórios dos advogados, carregados de papeladas inúteis e empoeiradas revelam a sujeira e obscuridade dos trâmites da corte de Chancery.

Um espaço que destoa da cidade de Londres é o centro metalúrgico do nordeste da Inglaterra, no qual impera a rapidez das chaminés das fábricas de ferro e dos fornos ardentes das minas de carvão. Ainda assim, é uma atmosfera carregada de fuligem. Esse espaço concentrou, no século

\footnotetext{
${ }^{17}$ MOISÉS, Massaud. Dicionário de Termos Literários. São Paulo: Cultrix, 2004.

18 "these tumbling tenements contain, by night, a swarm of misery. As on the ruined human wretch vermin parasites appear (...) in maggot numbers, where the rain drips in" (DICKENS,1853, p. 524).

19 "The Temple, Chancery Lane, Sarjeant's Inn e Lincoln's Inn, even unto the Fields are like tidal harbors at low water, where stranded proceedings, offices at anchor, idle clerks (...) lie high and dry upon the ooze of the long vacation" (DICKENS, 1853, p. 614).

20 "Both the world of fashion and the Court of Chancery are things of precedent and usage" (DICKENS,1853, p. 28).

21 "when all the stopped spits in the kitchen shall begin to turn prodigiously!" (DICKENS, 1853, p. 28).
} 
XIX, o desenvolvimento de uma elite industrial e construções importantes foram erguidas para atender aos anseios dessa nova classe, como o Theatre Royal e o Grainger Market na cidade de Newcastle. Enquanto isso, o ambiente produzido pelas fornalhas, rumores e faíscas de ferro constitui uma espécie de ameaça à ordem social vigente e também ao Tribunal.

Contudo, o único espaço do romance de Dickens que se contrapõe aos anteriores é a casa soturna (Bleak house). Outrora sombria, onde o antigo dono se suicidou de desencanto com a causa Jarndyce and Jarndyce, tornou-se arejada, limpa e organizada, quando o novo morador, John Jarndyce, estabeleceu a solidariedade entre os habitantes e a caridade com outros personagens. Essa casa foi posteriormente desdobrada em outra, também de mesmo nome, que o proprietário molda para a protagonista, Ester, a quem ele ampara desde a infância. Notam-se os valores positivos da descrição do imóvel: "encantadora", "linda vista", "confortável", "bela e larga janela", "flores de veludo"; "pétalas de rosa e suave alfazema". Desse modo, o lugar parece entrecruzar-se a um outro sistema de organização da justiça, baseado na ajuda mútua, como se a narrativa apontasse para uma nova maneira de resolução de problemas sociais que não estivesse subjugada ao Tribunal.

Já no romance de McEwan, o espaço concentra-se principalmente no bairro de Holborn, e conforme se afirmou anteriormente, é, na atualidade, um lugar privilegiado de Londres. Pode-se afirmar que as salas requintadas dos advogados, as livrarias e lojas elegantes especializadas em livros e roupas específicas para serem usadas nos tribunais, as grandes concessionárias de carros e os restaurantes refinados também se configuram como alegorias na medida em que apontam para o aspecto de pompa da Real Corte.

Nessa perspectiva de suntuosidade, o apartamento onde mora Fiona constitui-se como uma espécie de continuação do tribunal, para onde ela leva os processos, e é descrito contendo objetos que refletem os privilégios e comodidades que o cargo de juíza lhe proporciona, a chaise longue, um tapete Bokhara, o piano de cauda, fotos em molduras de prata, o whisky Talisker, etc.

Nas poucas vezes em que a narrativa focaliza outros espaços, distantes de Holborn, mantém-se a correspondência alegórica com a magnificência do jurídico. O hospital em que o protagonista, Adam Henry, ficou internado para se tratar de uma leucemia é um exemplo dessa prática. Trata-se de uma torre circular de vidro, com vinte e seis andares, cuja entrada continha um átrio envidraçado. No mezanino havia fonte, business center, floricultura e livraria. Toda a disposição dos corredores, postos de enfermagem, elevadores e salas de espera exibem extremo senso de organização e limpeza, ressaltadas por termos como: "polished corridor" (reluzente corredor), "antiseptic" smell, (cheiro de antisséptico), "closed doors" (portas fechadas), mas também apresentam um aspecto labiríntico. 
Outro espaço distante da corte de Chancery, descrita em The Children Act, é a região metalúrgica no nordeste da Inglaterra. Apresentada em Bleak House de forma futurista e ameaçadora, com faíscas produzidas pela forja dos ferros, é recriada por McEwan com uma atmosfera muito diferente daquela retratada por Dickens. Em contraste com o sucesso dos séculos XVIII e XIX, Newcastle e outras cidades dessa parte do país sofreram grande declínio no período entre guerras, e especialmente nos séculos XX e início do XXI, a falta de investimentos e o impacto do mercado asiático contribuíram para a decadência do lugar. Assim, a narrativa destaca que os prédios de ferro fundido e vidro da era vitoriana foram transformados atualmente em cafés e bares, em uma tentativa de livrá-los da decrepitude.

Fiona May viaja para algumas cidades inglesas dessa região, acompanhada de outro juiz, em um circuito itinerante, para julgar casos. É uma prática que se repete anualmente e nessas ocasiões, os juízes e seus assistentes ficam acomodados em mansões antigas, como o Leadman Hall, um palacete que a família não conseguia mais manter com recursos próprios e alugava para eventos. A propriedade é descrita por McEwan dessa maneira: "O palacete, no estilo do arquiteto Andrea Palladio e havia pouco tempo pintado de um branco brilhante demais, tinha doze quartos e nove empregados para servir a dois magistrados do Tribunal Superior em seu circuito itinerante" (MCEWAN, 2014a, p. 136). ${ }^{22}$

Repete-se, assim, mais uma vez, o caráter de suntuosidade e pompa relacionado à corte inglesa, entretanto, o próprio narrador observa que essa grandeza está ameaçada: "luxos desnecessários para juízes de passagem e muito atarefados" (MCEWAN, 2014b, p. 137) ${ }^{23}$, afirmando que essas práticas devem ser substituídas no ano seguinte por acomodações em um hotel central da cidade.

Não há nessa narrativa de McEwan bairro algum que se assemelhe ou retome o Tom-All-Alone's, de Dickens. Ocorre apenas referência a uma região empobrecida, e aparece no momento em que Fiona e a assistente social, Marina, estão no táxi a caminho do hospital:

Ela tinha a ignorância e o desdém de uma habitante da parte norte de Londres pelo labirinto interminável de ruas pobres que se estendia ao sul do Tâmisa. Nenhuma estação do metrô que desse significado a um emaranhado de vilarejos engolidos pela cidade fazia muito tempo, lojas tristes e garagens desonestas entremeadas de casas mambembes do período eduardiano e blocos horríveis de apartamentos, covis dominados por traficantes de drogas. As multidões de pedestres, absortas em preocupações que lhe pareciam estranhas, pertenciam a outra cidade, a uma longínqua cidade que não era a dela. Como saber que estavam atravessando Clapham Junction não fosse uma tabuleta desbotada e engraçada na fachada de uma loja de produtos elétricos fechada com tábuas? Reconhecendo em seu

\footnotetext{
22 "The hall, in the Palladian Style, recently painted a too brilliant White, had twelve bedrooms and nine staff to accommodate and serve two High Court judges on circuit" (MCEWAN, 2014b, p. 148).

23 "unnecessary luxuries for hard-working judges passing through" (MCEWAN, 2014b, p. 137).
} 
íntimo uma misantropia crescente, obrigou-se a relembrar o propósito da missão. Ia visitar um menino gravemente enfermo (MCEWAN,2014a, p. 89). ${ }^{24}$

Nota-se, no excerto acima, a utilização do discurso indireto livre, em que a voz da personagem aparece inserida na fala do narrador. Em "O discurso citado na construção do efeito de sentido de identidade em agentes de segurança penitenciária", HarKot-de-la-Taille (2008) ${ }^{25}$ traça relações entre a escolha do emprego de discurso direto, indireto e indireto livre com alguns percursos temáticos e figurativos formadores de efeito de sentido de identidade do sujeito, enquanto representação social. Para ela: "Apreender o intertexto exige, portanto, especial atenção às formas do discurso citado. $\mathrm{E}$ as formas legitimadas pela prática fornecem indícios do conjunto de valores subjacente ao discurso" (p. 481).

A escolha pelo discurso indireto livre no fragmento acima citado reproduz o pensamento da juíza mesclado à sondagem do narrador, delatando um julgamento problemático sobre uma esfera social por desconhecer o seu real funcionamento. A protagonista é responsável por aplicar a lei em uma sociedade retratada por essa via discursiva como distante e inferior à dela, inclusive, sugerindo um sentimento de culpa, que procura ser compensado imediatamente pela missão benevolente à qual se dirige para atender a um menino doente.

Assim, na medida em que imprime a construção do efeito de identidade da magistrada, a utilização do discurso indireto livre sugere uma relação com o próprio tribunal. É possível inferir que os membros da corte fazem parte de uma elite intelectual e liberal, com posições de comando na instância jurídica que mantém a ordem capitalista. Sobretudo, que existe uma "falha" nessa instituição, pois como a própria construção discursiva do espaço atesta, está muito mais próxima dos costumes burgueses do que da luta de classes e da pobreza, fato que poderia inviabilizar a condição de igualdade nos julgamentos e vereditos.

Tomando como exemplo o último fragmento citado, enquanto na narrativa de McEwan a crítica à corte aparece impressa no relato indireto e mesclado das vozes do narrador e da protagonista, no texto de Dickens, a denúncia às falhas da instituição jurídica é muito mais declarada, como se pode notar na citação seguinte:

\footnotetext{
${ }^{24}$ She had a north Londoner's ignorance of and disdain for the boundless shabby tangle of London south of the river. Not a Tube stop to give meaning and relation to a wilderness of villages swallowed up long ago, to sad shops, to dodgy garages interspersed with dust Edwardian houses and brutalist apartment towers, the dedicated lairs of drug gangs. The pavement crowds, adrift in alien concerns, belonged to some other, remote city, not her own. How would she have known they were passing through Clapham Junction without the faded jokey sign above a boardedup electrical store? Why make a life here? She recognized in herself the signs of an enveloping misanthropy and made herself remember her mission. She was visiting a seriously ill boy. (MCEWAN, 2014b, p. 93)

${ }^{25}$ HARKOT-DE-LA-TAILLE, Elizabeth. "O discurso citado na construção do efeito de sentido de identidade em agentes de segurança penitenciária". Disponível em:

http://www.dissoc.org/ediciones/v02n03/DS2\%283\%29Harkot.html . Acesso em 06/01/2017.
} 
Ver tudo aquilo deslizando de um modo tão macio, e pensar na rudeza das vidas e das mortes dos litigantes; ver toda aquela indumentária de gala e cerimônia, e pensar no desperdício, na necessidade, na miséria mendicante que ela representava; considerar que, enquanto a doença da esperança adiada causava estragos em tantos corações, essa exibição de polidez continuava calmamente dia a dia, ano a ano, na mesma boa ordem e compostura; contemplar o Lorde Chanceler e toda a enfiada de profissionais às suas ordens, olhando uns para os outros e para os espectadores, como se ninguém houvesse jamais ouvido dizer que, por toda a Inglaterra, o nome debaixo do qual todos eles estavam reunidos era uma pilhéria amarga: era tido em horror universal, em desprezo e indignação, era conhecido como sendo uma coisa tão escandalosa e tão má que só por um milagre bem pouco provável poderia daí sobrevir algum bem a qualquer pessoa (DICKENS, 1986, p. 317). ${ }^{26}$

Em Bleak House os capítulos são ora narrados por um narrador em terceira pessoa e ora pela protagonista em primeira pessoa. Na citação acima, observa-se essa segunda instância narrando por meio do discurso indireto. Assim, a voz é dada à personagem e reproduz o pensamento dela. Entretanto, essa voz afirma alinhar-se à de "toda a Inglaterra", a uma constatação "universal" que considera os membros do judiciário e "o nome debaixo do qual todos eles estavam reunidos", portanto, da corte, em completo desprestígio: "pilhéria amarga", "horror", "uma coisa tão escandalosa e tão má". Assim, a denúncia no livro de Dickens imprime ao texto um tom muito mais ácido e deliberado do que na narrativa de McEwan.

Deste modo, quando Brian Finney (2004) ${ }^{27}$ afirma que "O romance de McEwan é obviamente uma releitura do clássico romance realista do século XIX" (p. 71, tradução nossa) ${ }^{28}$, é preciso entender que o crítico está considerando o estilo, cuja principal atenção dos autores era reproduzir o mundo real com a máxima fidelidade possível e conferir aos personagens densidade psicológica. Fazem parte dessa vertente, entre outros, escritores como George Eliot, Henry James, as irmãs Brontë, Anthony Trollope e Thomas Hardy. Contudo, esse período artístico apresentou algumas ramificações, como a do realismo social, no qual as obras estão mais voltadas a retratar o processo de industrialização do período e a política social, mostrando os abusos dos governos, o sofrimento dos pobres, a luta

\footnotetext{
26 "To see everything going on so smoothly and to think of the roughness of the suitor's lives and deaths; to see all that full dress and ceremony and to think of the waste, and want, and beggared misery it represented; to consider that while the sickness of hope deferred was raging in so many hearts this polite show went calmly on from day to day, and year to year, in such good order and composure; to behold the Lord Chancellor and the whole array of practitioners under him looking at one another and at the spectators as if nobody had ever heard that all over England the name in which they were assembled was a bitter jest, was held in universal horror, contempt, and indignation, was known for something so flagrant and bad that little short of a miracle could bring any good out of it to any one" (DICKENS, 1853, p. 814).

${ }^{27}$ FINNEY, Brian. Briony's stand against oblivion: Ian McEwan's Atonement. Journal of Modern Literature, 27 (3). Bloomington: Indiana University Press. 2004, pp. 68-82.

28"McEwan's novel is most obviously, a rereading of the classic realist novel of the nineteenth century" (FINNEY, 2004, p. 71).
} 
de classes. Um dos principais representantes dessa corrente na literatura inglesa é Charles Dickens.

Nesse aspecto, os autores estudados diferem imensamente, visto que a literatura de McEwan não se configura como um tipo de narrativa que instiga à luta e apresenta o sujeito em tensão com a mentalidade dominante, mas antes, promove uma aproximação com o sentido da existência, da vida, das sensações, dos limites e liberdades da experiência humana no mundo. Os personagens do autor raramente pertencem às classes sociais menos favorecidas, pelo contrário, são, em sua maioria seres de uma elite intelectual e liberal, com posições de comando nas instituições às quais aparecem ligados. Entretanto, esse ambiente pomposo e burguês, bem como os seres que o compõem, aparece sempre marcado por falhas, de modo que o leitor entra em contato com erros em vereditos que causaram danos irreparáveis na vida das personagens, instigando o questionamento e a compreensão dos sistemas que se propõem a manter a ordem social, como o jurídico e o religioso.

\section{Conclusão}

Consideradas as particularidades de cada autor e do delineamento de seus textos sobre as circunstâncias históricas que os circundam, um traço marcante predomina nas obras estudadas: a expressão simbólica do espaço.

Bleak House precedeu em alguns séculos o romance de Ian McEwan, fornecendo o retrato de uma cidade corroída pelas diferenças sociais, pelo descaso do governo com questões básicas de infraestrutura e higiene, pelas transformações sociais oriundas do desenvolvimento industrial, e sobretudo, denunciando um sistema jurídico lento, ineficiente e corrupto, incapaz de assumir um imperativo ético para resolver problemas de disputas de propriedades e de testamentos, apontando para uma postura ideológica de igualdade e solidariedade.

Ao estabelecer um diálogo intertextual com o romance de Dickens, The Children Act ressalta as mudanças significativas que ocorreram na Inglaterra desde o século XIX, mostra a suntuosidade da capital inglesa nos bairros nobres, onde as cortes estão situadas, e o distanciamento desse ambiente com as regiões mais pobres da cidade. Em tom mais ameno que o do autor vitoriano, McEwan constrói uma denúncia dialética da instituição jurídica, evidenciando a rapidez e potência do sistema legal, paralelas às falhas da corte, sugerindo que a normatização social implica a repressão de emoções e crenças em nome de uma uniformidade de valores, levando o leitor a pensar se no cenário atual haveria condições de criar um sistema capaz de manter a ordem e a liberdade.

Assim, enquanto a narrativa de Dickens estabelece a caridade e a ajuda mútua como possibilidades de comunhão social, a visão de mundo 
presente na obra de McEwan é cética em relação ao entendimento entre os homens, parece que para ele, só mesmo a percepção das diferenças e a flexibilidade podem oferecer algum alento.

Tomando a construção literária como uma espécie de cenário capaz de recriar a crise, um lugar autônomo que não se apresenta como refúgio e não promete soluções para os problemas sociais, os dois autores colocam em evidência a própria representação da realidade por meio da linguagem poética.

O viés literário da abordagem do Direito representa, em ambos os romances, uma fonte de análise da manipulação dos discursos do poder, contribuindo para elucidar que o manejo da linguagem é um instrumento poderoso de persuasão. As obras analisadas reiteram também a força manipulativa do discurso artístico, pois deixam aparentes as estratégias utilizadas pelos autores, como a estruturação do espaço, do tempo e das personagens. A diferença entre esse discurso artístico e o jurídico, é que o primeiro não precisa se posicionar como detentor de uma ideologia inquestionável e nem carece de apresentar uma resolução para os conflitos humanos. 